\title{
PRE-TREATMENT TEMPERATURE AND MULTI-RESPONSE SURFACE OPTIMISATION OF ULTRASOUND-ASSISTED EXTRACTION OF ANTIOXIDANTS FROM RED DATES
}

\author{
Haripriya Ravikumar, Chua Bee Lin*, Chen Yen Leng, Ameena Ali, Choo Choong Oon
}

School of Computer Science and Engineering, Faculty of Innovation and Technology, Taylor's University, 1, Jalan Taylor's, 47500, Malaysia

Received - July 18, 2020; Revision - September 17, 2020; Accepted - December 08, 2020

Available Online - March 25, 2021

DOI: http://dx.doi.org/10.18006/2021.9(Spl-1-GCSGD_2020).S148.S160

KEYWORDS
Drying
Extraction
Optimisation
Response surface
methodology (RSM),
Red dates
Antioxidants

\begin{abstract}
Ziziphus jujube known as red dates are natural flora, are a rich source of antioxidant bioactive compounds and are widely used in making Chinese traditional medicine. However, the optimization of extraction conditions and demonstration of extraction kinetics of red dates remains a gap. Therefore, the main objective of this research was to enhance the antioxidant activity via DPPH, crude extract yield, and TPC by response surface methodology (RSM). Also, mathematical modeling of the TPC extraction kinetics was performed. Single-factor experiments were adopted to identify the preliminary RSM ranges of four extraction parameters such as liquid-solid ratio $(10,20$, and $30 \mathrm{ml} / \mathrm{g})$, extraction temperature (50, 60 and $70^{\circ} \mathrm{C}$ ), time $(40,50$ and $60 \mathrm{~min})$, and ultrasonic power $(70,80$ and $90 \%)$. The extraction kinetics based on RSM optimized conditions were modeled into six extraction kinetic models. As result, the highest crude extract yield (4.56 g), highest TPC (0.023 g GAE/g extract), and highest antioxidant activity $(85.88 \%)$ were obtained at $60^{\circ} \mathrm{C}$. The optimum values were liquid-solid ratio $30 \mathrm{ml} / \mathrm{g}$, extraction temperature $60^{\circ} \mathrm{C}$, time $60 \mathrm{~min}$, and ultrasonic power $70 \%$. The antioxidant activity of red dates after optimization $(90.59 \%)$ was higher than that of synthetic antioxidants, Butylated Hydroxytoluene ( $84.71 \%)$, and Butylated Hydroxyanisole $(77.73 \%)$. Furthermore, the best-fitted kinetic model was the second-order kinetic model due to its coefficient of determination $\left(R^{2}\right)$ at 0.9849 , being the closest to 1 and its root mean square error (RMSE) was the lowest, 0.001028 among other models.
\end{abstract}

* Corresponding author

E-mail: beelin.chua@taylors.edu.my (Chua Bee Lin)

Peer review under responsibility of Journal of Experimental Biology and Agricultural Sciences.

Production and Hosting by Horizon Publisher India [HPI] (http://www.horizonpublisherindia.in/).

All rights reserved.
All the articles published by Journal of Experimental Biology and Agricultural Sciences are licensed under a Creative Commons Attribution-NonCommercial 4.0 International License Based on a work at www.jebas.org.

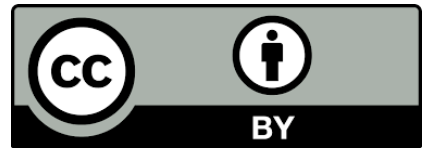




\section{Introduction}

Ziziphus jujuba Mil., referred as a red dates or Chinese dates belonging to the family Rhamnaceae, is a native fruit of Chinese culture (Ali et al., 2017; Bee Lin \& Yen Leng, 2018). It is an outstanding source of bioactive compounds whose properties range from nutritional to nutraceutical. Red dates contain a high amount of macronutrients, vitamins, and minerals that are highly beneficial for those suffering from health issues such as insomnia, blood pressure, and high cholesterol (Morales et al., 2014). Research had proven that the most pronounced attribute of red dates was its antioxidant potential. Recently, research on preservation and extraction of antioxidants from natural sources are more driven by the fact that synthetic antioxidants like BHT and BHA may possess health hazards and they are restricted to use in food materials since they are a potent source to cause liver damage (Balyan \& Sarkar, 2017). Thus, investigation of the antioxidant potential of red dates to prevent chronic disease is worthwhile. In a recent study on southern Morocco dates variety, the results revealed that total phenolic content and antioxidant activity are a promising source for antioxidants (Alahyane et al., 2019). Due to high nutritional and nutraceutical properties, there are limited study reported the optimization of extraction conditions which could result in increasing the yield of the crude extract along with higher TPC and antioxidant activity in red dates. Response surface methodology is also known as RSM optimization along with Box-Behnken Design (BBD) experimental design was commonly used due to its high coherence, lesser runs, and low cost (Anuar et al., 2013; Ali et al., 2018). However, there is limited study on the optimization of extraction conditions of red dates based on multiple responses simultaneously (crude extract yield, TPC yield, and antioxidant activity) (Ngo et al., 2017).

In real-life scenarios, extraction is not preceded immediately after the plant or plant parts are harvested. In such situations, high moisture content can promote microbial contamination, degrade the bioactive compounds, and ultimately results in loss of its antioxidant potential (Toğrul \& Pehlivan, 2004; Chua et al., 2019a; Chua et al., 2019b; Choo et al., 2020). Thus, drying is implemented to enhance the quantity and quality of the plant and plant parts for further processing. High temperature may induce degradation of the compounds and low temperature may not have enough energy to remove the moisture to the desired level. Therefore, the oven drying method is more convenient and its drying process is uniform. Besides that, rapid evaporation of water takes place in the oven due to high vaporization. Thus, the present study aimed to identify the appropriate drying temperature that yields high TPC and antioxidants in red dates for future reference. On large scale, solid-liquid extractions are enforced to acquire the crude extract from any medicinal herb. Extraction techniques have evolved from the conventional (maceration, soxhlet, and distillation) to non-conventional (microwave-assisted (MAE), ultrasound-assisted (UAE), supercritical fluid (SFE), pulse electric, enzyme assisted, pressurized liquid, pressurized hot water) extraction techniques. Among all extraction methods, the ultrasound-assisted extraction method (UAE) is the method opted by researchers in terms of simplicity and effectiveness with reduced solvent and energy usage (Ali et al., 2018). Its fundamental benefit lies in its potential to extract and retain the bioactive compounds at a relatively low temperature without compromising the yield with equal effectiveness (Dias et al., 2017).

Mathematical modelling provides a swift and inexpensive method to determine, predict and control the extraction process. Both statistical and empirical approaches are adopted by researchers for the complete conception of the entire process and the significant factors that influence them. From a statistical point of view, response surface methodology (RSM) is implemented to examine and optimize the whole process. When the empirical approach is concerned, kinetic models are utilized to investigate the kinetics of the process (Dias et al., 2017). Response surface methodology (RSM) has been successfully implemented in the previous works to optimize the extraction of antioxidants. The most widely used kinetic models for describing the extraction of antioxidants are the logarithmic model, Peleg's model, second-order rate law, Page's model, Ponomaryov's model, two-site kinetic model, Power-law, Fick's law of diffusion (Ali et al., 2018). As far as our understanding, there remains a major gap involving the preservation and extraction of antioxidants from red dates efficiently and effectively. Thus, it is important to study the drying and extraction processes of red dates which affect the phenolic content and antioxidant activity. Firstly, the current study aimed to identify the best drying temperature of the antioxidants in red dates. Secondly, study was conducted to adopting both statistical and empirical approaches. The goal of prevailing research is also to determine the effectiveness of ultrasound on the extraction of antioxidants from red dates and optimise its extraction conditions via RSM and kinetics modelling. Furthermore, the comparison will be drawn between the optimised red dates extract and synthetic commercial antioxidants (BHT and BHA) to ascertain the antioxidant potential of red dates.

\section{Materials and Methods}

\subsection{Chemical Reagent}

The reagents and solvents used for this study were gallic acid, 99.9\% ethanol (HPLC grade 99.9\%), FC reagent, sodium carbonate $\left(\mathrm{Na}_{2} \mathrm{CO}_{3}\right)$, and DPPH (2,2-diphenyl-1-picrylhydrazyl). Chemicals mentioned above are purchased from Evergreen 
Engineering \& Resources (Evergreen Engineering \& Resources Sdn. Bhd., Selangor, Malaysia) and Chemolab (Chemolab Supplies Sdn. Bhd., Selangor, Malaysia).

\subsection{Preparation and Pre-Treatment of Red Dates}

Red dates $(900 \mathrm{~g})$ were purchased and thoroughly washed with distilled water before the seeds of the fruits were removed. The initial weight was measured by a digital balance (TX423L, Shimazdu Corporation, Japan). About $50 \mathrm{~g}$ of red dates were dried using an air-forced convective oven (Model UN75, Memmert, Germany) at different temperatures of $50^{\circ} \mathrm{C}, 60^{\circ} \mathrm{C}, 70^{\circ} \mathrm{C}$, and $80^{\circ} \mathrm{C}$ until a persist weight was noted. The dried dates were ground to powder with help of a household blender and stored for future use. Subsequent analysis of crude extract yield, total phenolic content, and antioxidant activity (described in subsequent sections) were implemented by the extraction method reported in section 2.3 to identify the optimum pre-treatment temperature before extraction (Bee Lin \& Yen Leng, 2018).

\subsection{Ultrasound-Assisted Extraction (UAE) and Total Phenolic Content (TPC) Analysis of Red Dates}

Ultrasound-assisted extraction of red dates was conducted according to the procedures reported in previous research with slight modifications (Al Harthi et al., 2015; Ali et al., 2017) Powdered red dates were extracted with ethanol $(1: 15 \mathrm{~g} / \mathrm{ml})$ for an hour in an ultrasonic bath $(\mathrm{P} 120 \mathrm{H}$, Elmasonic, Germany). The sonicated water bath functioned at $60^{\circ} \mathrm{C}, 70 \%$ input power, and 37 $\mathrm{kW}$ of operating frequency. Following the extraction, the mixture was filtered using Whatman filter paper no. 1. The supernatant was evaporated using a rotary vacuum evaporator (Hei-VAP Platinum 3 , Heidolph, Germany) at $40^{\circ} \mathrm{C}$ and 1 bar. The dried crude extract was stored under $4^{\circ} \mathrm{C}$ for further analysis.

\subsection{Quantification of Crude Extract Yield and TPC from Red Dates}

The crude extract yield was measured using an analytical balance (HR-250AZ, A\&D, Japan) and equation (1). To determine the TPC in the respective extract, $1 \mathrm{~g}$ of Folin-Ciocalteu (FC) phenol reagent was mixed with $99.9 \mathrm{ml}$ of deionized water to prepare $10 \%$ (v/v) of Folin-Ciocalteu phenol reagent solution (Qu et al., 2010). Further, $7 \%$ of sodium carbonate $\left(\mathrm{Na}_{2} \mathrm{CO}_{3}\right)$ solution was prepared in the same manner. Samples were developed by dissolving $1 \mathrm{~g}$ of crude extract in $15 \mathrm{ml}$ of distilled water. To the above extract, $5 \mathrm{ml}$ of $10 \% \mathrm{FC}$ reagent, $4 \mathrm{ml}$ of $7 \% \mathrm{Na}_{2} \mathrm{CO}_{3}$ solution, and sample extracts were all mixed and kept at room temperature $\left(26^{\circ} \mathrm{C}\right)$ for an hour. About $0.2 \mathrm{ml}$ of the resulting solution was poured into 96 well plate and the absorbance was noted via microplate spectrophotometer at 765 (Epoch 2, BioTek, USA). Pure ethanol was used as a blank solution. TPC in red dates extract was determined regarding the gallic acid calibration curve $\left(r^{2}=0.9792\right)$ that was procured similarly. The experiments were performed in triplicates and denoted as g gallic acid equivalent/g of dried weight extract \pm standard deviation.

$$
\text { Crude extract yield }=\frac{W_{c}}{W_{d}} \times 100 \%
$$

Where $\mathrm{W}_{\mathrm{c}}$ and $\mathrm{W}_{\mathrm{d}}$ are the weight of the crude extract and red date powder sample in grams, respectively.

\subsection{Determination of the Antioxidant Activity of Red Dates}

To determine the antioxidant potential of red dates, DPPH analysis was used with slight modifications (Qu et al., 2010). About $270 \mu \mathrm{l}$ of $0.1 \mathrm{mM}$ DPPH solution in ethanol was added to $30 \mu \mathrm{l}$ of sample extract and the resulting mixture was kept in dark for about 30 $\mathrm{min}$. Later, $0.2 \mathrm{ml}$ of the same mixture was transferred into a 96well plate and the absorbance of the samples was read by microplate spectrophotometer at $515 \mathrm{~nm}$. The antioxidant activity was calculated using Equation. (2). Each procedure was repeated thrice and values were expressed as $\%$ activity \pm standard deviation.

Scavenging activity $(\%)=\frac{\mathrm{Abs}_{\text {control- }} \mathrm{Abs}_{\text {sample }}}{\mathrm{Abs}_{\text {control }}} \times 100 \%$

Where $A b s_{\text {control }}$ is the absorbance of the control sample and $A b s_{\text {sample }}$ is the absorbance of the extracted sample (Chua et al., 2019a; Choo et al., 2020).

\subsection{Identification of Best Drying Temperature and Response Surface Methodology (RSM) Optimisation}

The drying of red dates and extraction procedures were described in sections 2.2 and 2.3. Four different drying temperatures with a $10^{\circ} \mathrm{C}$ interval $\left(50\right.$ to $\left.80^{\circ} \mathrm{C}\right)$ were studied. Single-factor experiments were performed based on the selected drying temperature to investigate their impact on three targeted responses (crude extract yield, TPC, and antioxidant activity). The preliminary response surface methodology (RSM) operating ranges of the extraction parameters were identified and validated from single-factor experiments (Kang et al., 2019; Choo et al., 2020).

$$
Y=\beta_{\mathrm{o}}+\sum^{\mathrm{k}} \beta_{\mathrm{i}} \mathrm{x}_{\mathrm{i}}+\sum^{\mathrm{k}} \beta_{\mathrm{ii}} \mathrm{x}_{\mathrm{i}}^{2}+\sum_{\mathrm{i}}^{\mathrm{k}} \sum^{\mathrm{s}} \beta_{\mathrm{ij}} \mathrm{x}_{\mathrm{i}} \mathrm{x}_{\mathrm{j}}
$$

\subsection{Optimisation of Extraction Conditions and Validations of Optimum Extraction Conditions}

A four-factor, three-level Box-Behnken experimental Design (BBD) with a total of 28 runs was adopted to optimize the 
ultrasound-assisted extraction of antioxidants from red dates $(\mathrm{Qu}$ et al., 2010) using Design Expert Software Ver. 7.0 (Stat-Ease Inc, Minneapolis, USA). The three responses for optimization, namely crude extract yield $\left(y_{1}\right)$, TPC $\left(y_{2}\right)$, and DPPH scavenging activity $\left(y_{3}\right)$ were fitted to a second-order polynomial regression equation Eq. (3).

Where $Y$ is the response variable, and $X_{i}$ and $X_{j}$ are the independent variables ( $i$ and $j$ range from 1 to $k$ ), $\beta_{o}$ is a constant, $\beta_{i,} \beta_{i i}$, and $\beta_{i j}$ are the regression coefficients of linear, quadratic, and interactive terms respectively, $k$ is the number of parameters ( 4 for present research).

Table 2 shows the BBD runs, experimental and predicted responses which are average of triplicate experiments \pm standard deviation. Analysis of variance (ANOVA) was used to identify the significance $(\rho<0.05)$ of the developed models as well as the extraction parameters. The optimum conditions were validated with additional experiments and the differences between the experimental and predicted results of the responses $\left(y_{1}, y_{2}\right.$, and $\left.y_{3}\right)$ were calculated using Eq. (4).

$$
\text { Difference }(\%)=\frac{\left|y_{\text {experimental }}-\mathrm{y}_{\text {predicted }}\right|}{\mathrm{y}_{\text {experimental }}} \times 100 \%
$$

\subsection{Extraction Kinetic Modelling of Red Dates and Validation}

The kinetic models of interest for the present study were Page's model, first-order, second-order, Peleg's model, Logarithmic model, and Ponomaryov's model kinetic model. All six models were used to elucidate the extraction parameters of TPC (Table 1). The kinetic models were solved and the statistical coefficient of $\mathrm{R}^{2}$ and RMSE were determined using Microsoft excel solver (Microsoft Excel 2010, USA) and Matlab curve fitting tool (The MathWorks Inc., USA). The final results of the best-fitted kinetic model was obtained by comparing the experimental and predicted values of TPC under controlled conditions for three different extraction periods of 45,65 , and $85 \mathrm{~min}$.

Table 1 Popular Extraction Kinetic Models for Plants Model

\begin{tabular}{|c|c|c|c|c|}
\hline Name & Equation & Range of Constants & Applications & Reference \\
\hline \multirow[b]{2}{*}{ Peleg's } & \multirow{2}{*}{$C(t)=\mathrm{C}_{0}+\frac{t}{\mathrm{~K}_{1}+\mathrm{K}_{2} t}$} & $\mathrm{~K}_{1}: 0.063-4.414$ & \multirow{2}{*}{$\begin{array}{l}\text { Asteraceae plants, } \\
\text { vinifera, pomegranate } \\
\text { Soybeans }\end{array}$} & \multirow{2}{*}{$\begin{array}{l}\text { Jokic et al., 2010; Qu } \\
\text { et al., } 2010\end{array}$} \\
\hline & & $\mathrm{K}_{2}: 0.025-0.039$ & & \\
\hline \multirow[b]{2}{*}{ Page's } & \multirow[t]{2}{*}{$C(t)=-e^{-\mathrm{k} t^{\mathrm{n}}}$} & k: -2.737-(-0.297) & \multirow{2}{*}{$\begin{array}{l}\text { Asteraceae plants, Theobroma } \\
\text { cacao, soybeans }\end{array}$} & \multirow{2}{*}{$\begin{array}{l}\text { Jokic et al., 2010; Hii } \\
\text { et al., } 2009\end{array}$} \\
\hline & & $\mathrm{n}: 0.055-0.481$ & & \\
\hline \multirow[b]{2}{*}{ Ponomaryov's } & \multirow{2}{*}{$1-\frac{q_{i}}{q_{e}}=\mathrm{b}+\mathrm{k}_{1} t$} & b: $0.754-0.773$ & \multirow[b]{2}{*}{ Pomegranate marc, barley } & \multirow[b]{2}{*}{$\begin{array}{l}\text { Qu et al., 2010; } \\
\text { Paunović et al., } 2014\end{array}$} \\
\hline & & $\mathrm{k}_{3}: 0.00076-0.00103$ & & \\
\hline First Order & $C_{t}=C_{e}\left(1-e^{-k_{1} t}\right)$ & $\mathrm{k}_{1}: 0.00794-0.187$ & Jamun, Tilia sapwood & 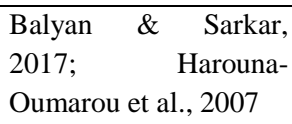 \\
\hline Second Order & $C_{t}=\frac{C_{e}^{2} \mathrm{k} t}{1+C_{e} \mathrm{k} t}$ & $\mathrm{k}_{2}: 0.115-6.314$ & $\begin{array}{l}\text { Pomegranate marc, Asteraceae } \\
\text { plants }\end{array}$ & Qu et al., 2010 \\
\hline \multirow[b]{2}{*}{ Logarithmic } & \multirow[t]{2}{*}{$C(t)=\mathrm{a} \cdot \log t+\mathrm{b}$} & a: $2.466-6.3379$ & \multirow[b]{2}{*}{ Asteraceae plants, soybeans } & \multirow[b]{2}{*}{ Guerrero et al., 2008} \\
\hline & & b:-3.277-14.447 & & \\
\hline
\end{tabular}

Here $C(t)$ : Concentration of TPC at time t, $C_{0}$ : Initial concentration of TPC, $C_{\mathrm{e}}$ : Equilibrium concentration of TPC in extract, $\mathrm{K}_{1}:$ Peleg's rate

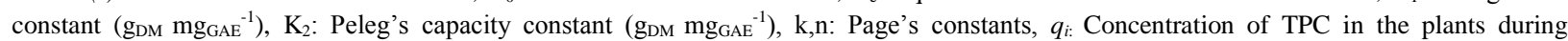
extraction, $q_{\mathrm{e}}$ : Equilibrium concentration of TPC in the plants, b: Washing coefficient, $\mathrm{k}_{3}$ : Slow extraction coefficient $\left(\min ^{-1}\right)$, $\mathrm{k}_{1}$ : first order rate constant $\left(\min ^{-1}\right) ; \mathrm{k}_{2}$ : second order rate constant ( $\left.\mathrm{g}_{\text {powder }} / \mathrm{mg} \min \right)$, a, b: Logarithmic constants 
3 Results and Discussion

3.1 Impact of Drying Temperature on Antioxidant Activity of Red Dates

The impact of four different drying temperatures on red dates was investigated based on crude extract yield, TPC, and antioxidant activity (Table 2). The results portrayed at $60^{\circ} \mathrm{C}$ had the highest yield $(4.56 \mathrm{~g})$, TPC $(0.023 \mathrm{~g} \mathrm{GAE} / \mathrm{g}$ extract), and DPPH antioxidant activity ( $85.88 \%$ activity) among the four temperatures investigated. The heat energy produced at this temperature was sufficient to disintegrate the bonds linking phenolic compounds and the insoluble fibres of red dates (Qu et al., 2010).
Thus, the resulting antioxidant activity was improved with increased phenolic content extraction at $60^{\circ} \mathrm{C}$. An incremental decrease in the results was observed beyond $60^{\circ} \mathrm{C}$ drying temperature. This might due to the thermal degradation of TPC that occurred at temperatures above $70^{\circ} \mathrm{C}$. The loss of TPC decreased the antioxidant activity of red dates. The current findings are consistent with previous reports (López-Vidaña et al., 2016). Thus, a drying temperature of $60^{\circ} \mathrm{C}$ was used to dry the red dates for further extraction stages.

Table 2 Effects of Drying Temperature on Antioxidant Activity, TPC and Crude Extract Yield

\begin{tabular}{|c|c|c|c|}
\hline Temperature $\left({ }^{\circ} \mathrm{C}\right)$ & Crude extract yield $(\mathrm{g})$ & $0.022 \pm 0.00006$ & Antioxidant activity $(\%)$ \\
\hline 50 & $4.44 \pm 0.067$ & $0.023 \pm 0.00009$ & $85.18 \pm 0.98$ \\
\hline 60 & $4.56 \pm 0.089$ & $0.022 \pm 0.00004$ & $85.88 \pm 1.24$ \\
\hline 70 & $4.41 \pm 0.022$ & $0.021 \pm 0.00001$ & $84.71 \pm 0.75$ \\
\hline 80 & $4.37 \pm 0.038$ & & \\
\hline
\end{tabular}

\subsection{Single-Factor Experimental Design}

Preliminary single factor experimental design was conducted to identify the response surface methodology (RSM) ranges for four extraction factors: liquid-solid ratio, extraction temperature, time, and ultrasonic power. The enactment of each factor on crude extract yield, TPC, and antioxidant activity are detailed in section 3.2.1 to 3.2.4 and the respective graphs are provided in online resource (Bee Lin \& Yen Leng, 2018).

\subsubsection{Impact of Solid-Liquid Ratio on Crude Extract Yield, TPC and Antioxidant Activity}

The solid-liquid ratio is a significant factor that affects the crude extract yield, TPC, and antioxidant activity. Based on the results, the extract yield increased with a gradual rise in the ratio. The maximum extract yield of $1.905 \mathrm{~g}$ was achieved at the highest amount of $30 \mathrm{ml} / \mathrm{g}$. At high ratios, more solvent was present in the extracting solution creating a higher concentration gradient that allowed the larger mass transfer of the system (Ali et al., 2018).

Moreover, the rate of diffusion was high because of the increase in the surface contact area between solvent and sample. TPC and DPPH antioxidant activity followed the trend of extract yield where the highest values of $0.0277 \mathrm{~g} \mathrm{GAE} / \mathrm{g}$ extract and
$91.69 \%$ antioxidant activity were also obtained at $30 \mathrm{ml} / \mathrm{g}$. Therefore, the optimum range of the liquid-solid ratio used for optimization was 10,20 , and $30 \mathrm{ml} / \mathrm{g}$. Similar findings were reported in a recent study (Alahyane et al., 2019). Hence, from the recent and current study, it is more evident that dates are loaded with high antioxidants.

\subsubsection{Impact of Ultrasonic Power on Crude Extract Yield, TPC and Antioxidant Activity}

Based on the results, all three outcomes increased with an increase in ultrasonic power. These outcomes might be caused by the formation and collapse of cavitation bubbles which was directly proportional to the amplitude of ultrasonic waves that passed through the medium (Kong et al., 2015). The larger frequency at high ultrasonication power led to intensified cavitation and the resulting shear stress caused by microstreaming from cavitation disrupted the cell wall. This mechanism accelerated the penetration of the solvent and released the antioxidants into and from red dates (Chemat et al., 2017). The highest yield (1.785\%), TPC $(0.0198 \mathrm{~g}$ GAE/ g extract), and DPPH antioxidant activity (86.1176\% activity) of red dates were noted at $90 \%$ ultrasound power. At the same time, it was also noted that the results showed a drastic 
decrease after $90 \%$ ultrasound power in all three aspects. The undesired outcomes might be due to the disintegration of the bioactive compounds and subsequently degraded its antioxidant potential. Previous studies had shown that high ultrasonication power increased the temperature of the extracting solvent which in turn degraded the thermos sensitive compounds and ultimately caused it to lose its properties (Zhou et al., 2017). Thus, the optimized ultrasonic power range was 70,80 , and $90 \%$.

\subsubsection{Impact of Extraction Temperature on Crude Extract Yield, TPC and Antioxidant Activity}

Temperature rise rapidly favoured the extraction process, particularly TPC and DPPH antioxidant activity. The increasing temperature reduced the solvent viscosity and surface tension. This positively enhanced the cavitation mechanism (Qu et al., 2010). As a result, the collapse of the cavitational bubbles occurred and augmented the release of antioxidants from within. Furthermore, the swelling and loosening effect resulted from the thermal effect at high temperature might increase the diffusivity of the solvent into the red dates' matrix and improved the mass transfer of the system (Moorthy et al., 2017). The best results of extraction yield $(1.805 \mathrm{~g})$, TPC (0.0232 g GAE/g extract), and DPPH antioxidant activity $\left(85.333 \%\right.$ activity) were achieved at $60^{\circ} \mathrm{C}$.

It is also known that high temperatures may also result in degradation of the phenolic content as observed during the experiments of ultrasound power. Similar results were also noted as temperature beyond $60^{\circ} \mathrm{C}$ reduced all three outcomes. Thus, it can be said with certainty that the phenolic content in red dates is thermos-sensitive and attention must be paid to this variable during the extraction process. Considering all factors, the appropriate temperature range of extraction for optimization was 50,60, and $70^{\circ} \mathrm{C}$.

\subsubsection{Impact of Extraction Time on Crude Extract Yield, TPC and Antioxidant Activity}

A positive effect on extraction time was observed on all three results. The best outputs of extraction yield $(2.007 \mathrm{~g})$, TPC $(0.0225$ g GAE/g extract), and DPPH antioxidant activity (80.7843\% activity) were obtained at $50 \mathrm{~min}$ extraction duration. The fibrous structure of red dates would require a certain amount of time for effective extraction of the antioxidants. The initial increase in the outcomes could be attributed to the straightforward mechanism of ultrasound that rendered the plant cells during $50 \mathrm{~min}$ for effective extraction to take place. The results began to decline past this point could be due to several reasons. Firstly, the loss of the phenolic compounds that led to the degradation of its antioxidant potential might be caused by the overexposure of ultrasound waves and excess heating over time. The degradation of antioxidant activity is due to the structural disintegration of phenolic compounds (Alzorqi et al., 2017). Secondly, the extraction of insoluble impurities due to the rupture of the red date's cell wall might lower the solvent's permeability into the fruit's matrix $(\mathrm{Qu}$ et al., 2010). From the results obtained, the selected optimum time range of extraction for RSM optimization was 40 to $60 \mathrm{~min}$.

\subsection{RSM Optimisation}

Adopting the results of the single-factor experiments, antioxidant extraction from red dates were optimized for the principal parameters of solid-liquid ratio (A), ultrasonic power (B), extraction temperature $(C)$, and extraction time (D) following the BBD experimental design. BBD design with the responses of crude extract yield, TPC, and DPPH antioxidant activity obtained for each run is presented in Table 3.

The data of yield, TPC, and antioxidant activity ranged in between 0.845 and $2.175 \mathrm{~g}, 0.0155$ and $0.032 \mathrm{~g} \mathrm{GAE} / \mathrm{g}$ extract, 67.97 and $96.36 \%$ activity, respectively. Since the primary goal of this present research is to escalate the antioxidant capacity of the red dates, optimization was held only by focusing on the results of DPPH antioxidant with the highest desirability throughout numerical optimization.

\subsubsection{Second-Order Polynomial Regression Model Fitting}

Three different quadratic models were developed for three responses using multiple regression analysis. ANOVA was adopted to analyze the variables and the RSM models where significance was considered when $\rho<0.05$.

Additionally, F-test was also conducted to further verify the importance of the variables statistically. The final developed models excluding the non-significant terms of each response were given in Eqs. (4), (5), and (6). Overall, the developed models for crude extract yield, TPC and DPPH antioxidant activity were found to be significant with F-values of 5.08 ( $\rho=0.0029), 5.78$ ( $\rho$ $=0.0016)$ and $8.83(\rho=0.0002)$, respectively. Additionally, the correlation coefficient $\left(\mathrm{R}^{2}\right)$ of the three models were found to be $0.8455,0.8042$, and 0.8840 showing a strong correlation between the experimental and predicted responses (Moorthy et al., 2017).

The adjusted correlation coefficients $\left(\mathrm{R}^{2}\right)$ for all three models were determined to be $0.7412,0.7670$, and 0.8352 , respectively. Besides, the absence of fit was not statistically significant in all instances (Xu et al., 2017). Coefficient of variance (CV) less than $10 \%$ and adequate precision greater than 4 was highly desirable (Ali et al., 2018). CV for crude extract yield (7.86), TPC (8.56), and antioxidant activity (4.05) together with adequate precision for crude extract yield (16.4715), TPC (14.4323), and antioxidant activity (14.9205) solidified the validity of the developed models. 
Crude extract yield $=-19.0265+0.0323 \mathrm{~A}+0.3460 \mathrm{C}+0.3526$ D-0.00275CD-0.001555C ${ }^{2}-0.001743 \mathrm{D}^{2}$

$$
\begin{aligned}
& \mathrm{TPC}=0.028-0.002498 C+0.001725 D- \\
& 0.0026 B C-0.0066 C^{2}
\end{aligned}
$$

DPPH antioxidant activity $=-472.8267+1.02092 \mathrm{~A}+1.78563 \mathrm{I}$ $+13.76460 \mathrm{C}+2.28608 \mathrm{D}+0.032353 \mathrm{BC}-0.031961 \mathrm{CD}-$ $0.024037 \mathrm{~B}^{2}-0.125086 \mathrm{C}^{2}$

The results of ANOVA revealed some quite interesting outputs as it would seem ultrasound power did not have any statistically significant influence on the responses except for antioxidant activity. Furthermore, its negative quadratic effect can be observed for the antioxidant activity only. On the other hand, extraction temperature and time had a high significantly positive linear as well as negative quadratic influence on all three responses. Total phenolic content was not influenced by the liquid-solid ratio, however, this variable had a significant positive linear influence on both crude extract yield and DPPH antioxidant activity. The interactivity between ultrasound power and temperature had both positive and negative effects on TPC and antioxidant activity, respectively. Lastly, the interaction between time and temperature have a significant negative influence on crude extract yield.

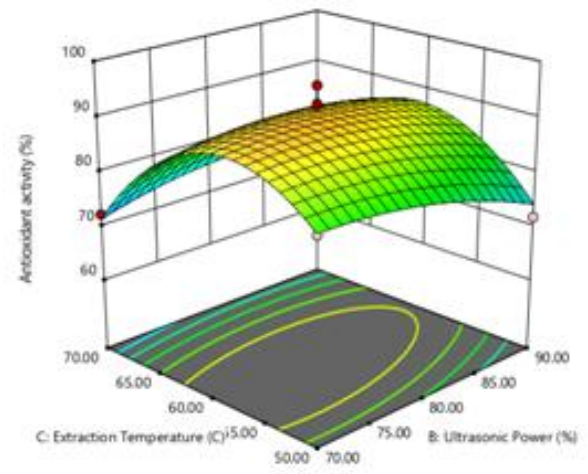

(1)

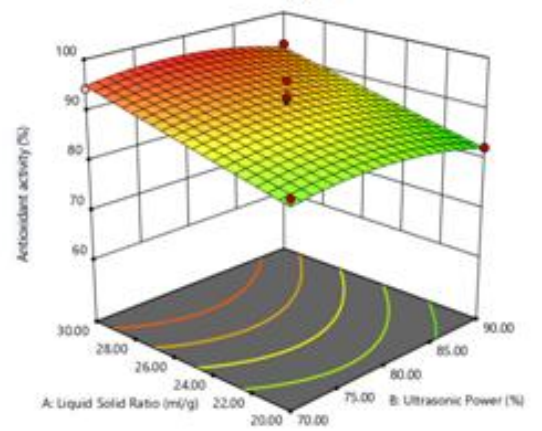

(3)
In other words, it can be said with certainty that the two factors that majorly influenced the extraction of antioxidants from red dates are none other than temperature and time. The 3D response plots graphically showing the effects of the independent variables on all three responses are provided in Figure 1.

The results of ANOVA revealed some quite interesting outputs as it would seem ultrasound power did not have any statistically significant influence on the responses except for antioxidant activity. Furthermore, its negative quadratic effect can be observed for the antioxidant activity only. On the other hand, extraction temperature and time had a high significantly positive linear as well as negative quadratic influence on all three responses. Total phenolic content was not influenced by the liquid-solid ratio, however, this variable had a significant positive linear influence on both crude extract yield and DPPH antioxidant activity. The interactivity between ultrasound power and temperature had both positive and negative effects on TPC and antioxidant activity, respectively. Lastly, the interaction between time and temperature have a significant negative influence on crude extract yield. In other words, it can be said with certainty that the two factors that majorly influenced the extraction of antioxidants from red dates are none other than temperature and time. The $3 \mathrm{D}$ response plots graphically showing the effects of the independent variables on all three responses are provided in Figure 1.

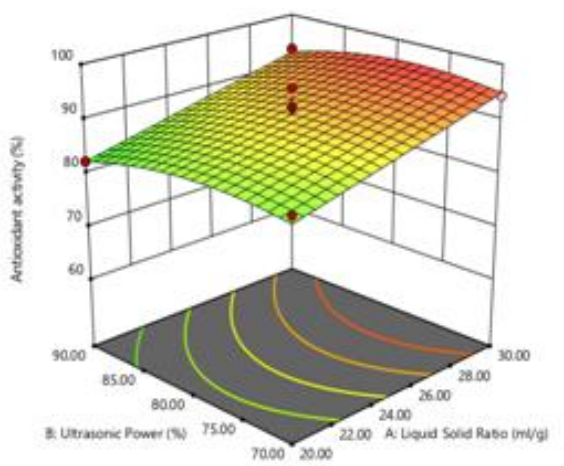

(2)

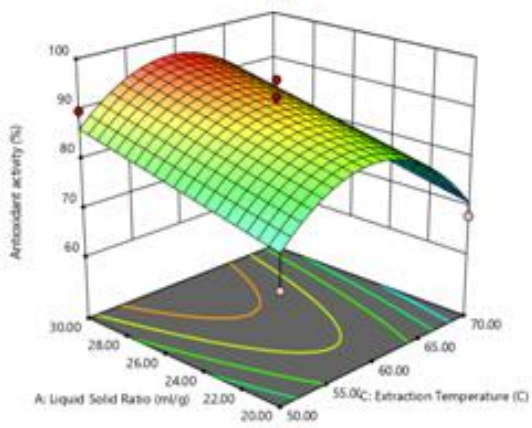

(4)

Journal of Experimental Biology and Agricultural Sciences http://www.jebas.org 


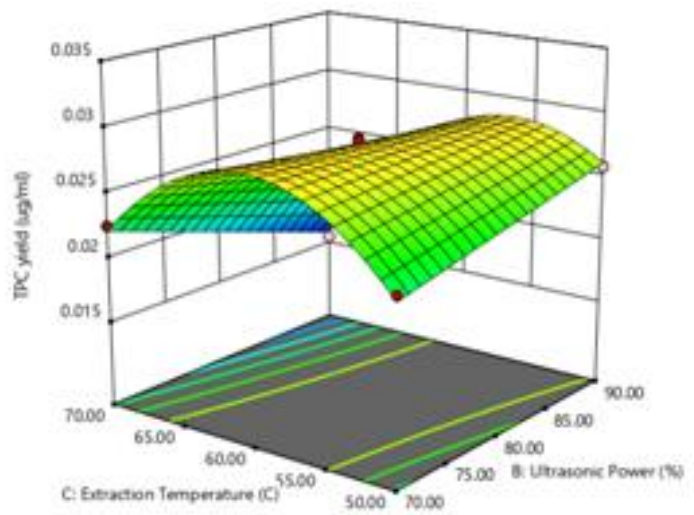

(5)

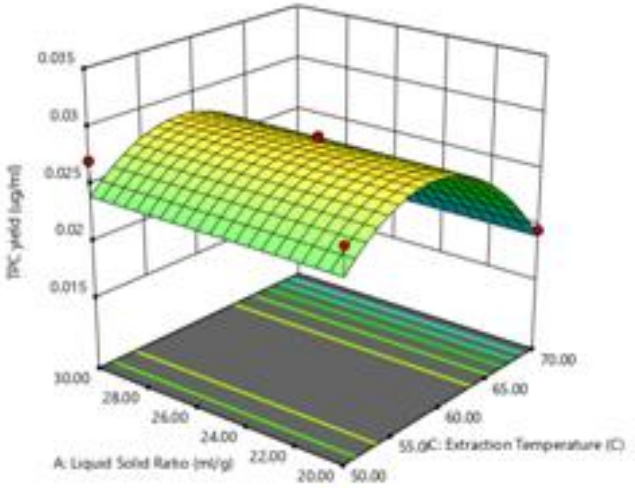

(7)

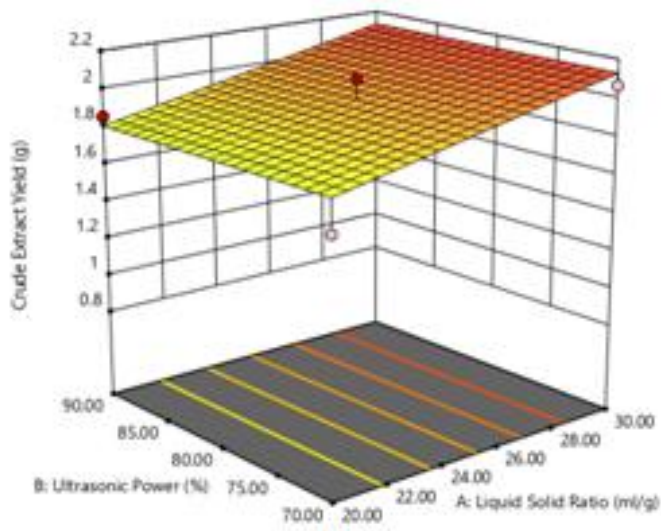

(9)

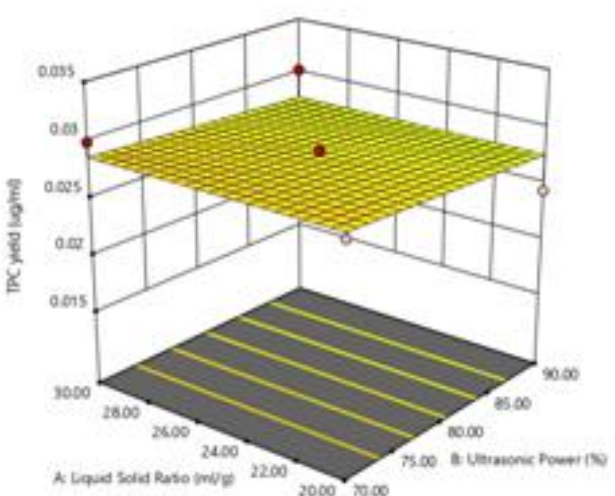

(6)

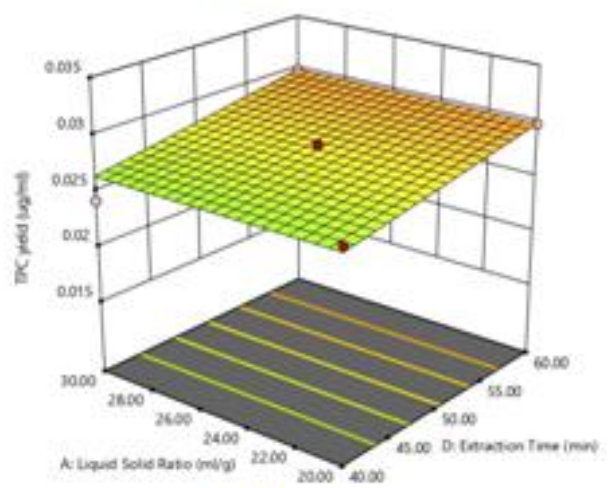

(8)

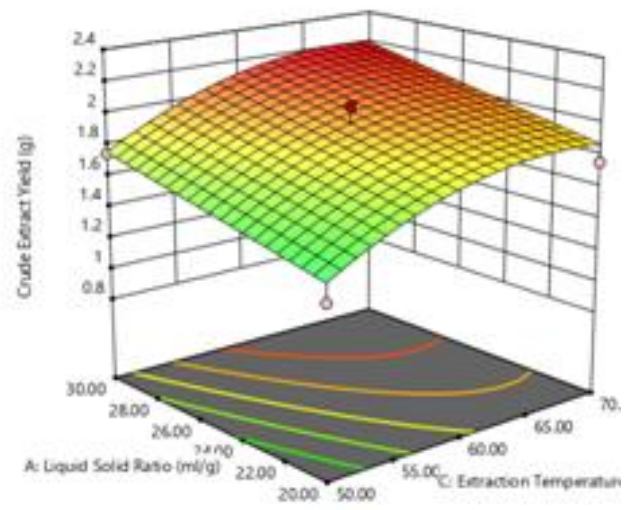

(10) 


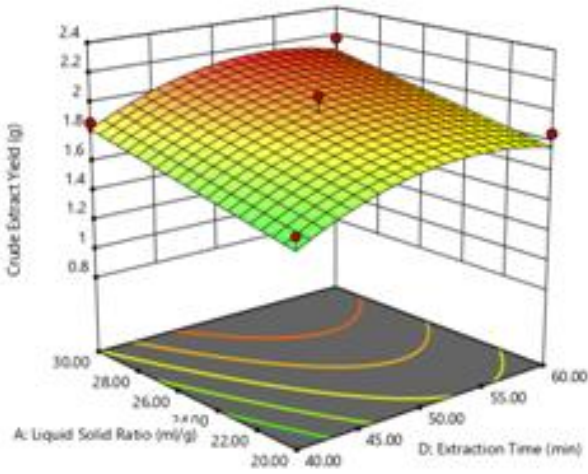

(11)

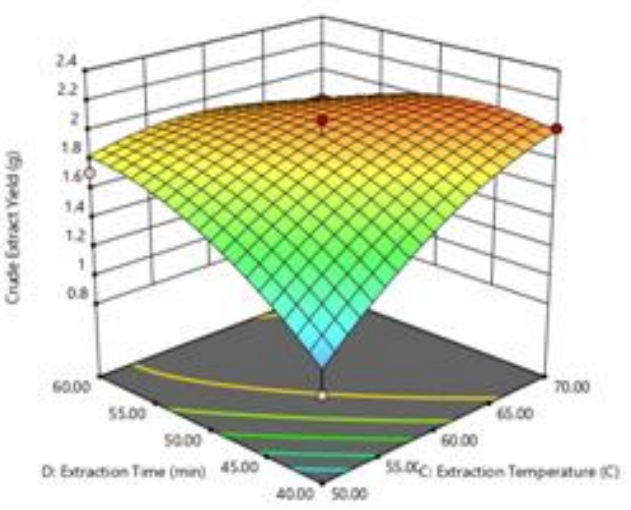

(12)

Figure 1 3D Response Plots of the Effect of Extraction Variables on (1-4) DPPH Antioxidant Activity, (5-8) TPC of Red Dates and (9-12) the Crude Extract Yield of Red Dates

\subsubsection{Numerical Optimisation and Validation}

Numerical optimization was adopted to optimize the independent extraction variables that displayed the highest antioxidant activity of red dates based on the three developed models. The optimum extraction condition was found to be at $58.55^{\circ} \mathrm{C}$ with power, ratio, and time of $70 \%, 30 \mathrm{ml} / \mathrm{g}$, and $59.93 \mathrm{~min}$. Further, the validity of models was tested using validation experiments. The experimental value of DPPH antioxidant activity under optimum condition was $90.59 \%$ whereas the predicted response was $98.24 \%$. Since the difference between experimental and prediction antioxidant value was $8.44 \%$, validation of the data was executed.

Besides, the RSM-optimised antioxidant activity of red dates was compared with two commercial synthetic antioxidants to validate their potential. Both BHT (84.71\%) and BHA (77.73\%) showed a significantly lesser antioxidant activity than red dates $(90.59 \%)$. Thus, verifying as a strong alternate source of natural antioxidant in future industrial applications.

\subsection{Comparison of Extraction Kinetic Models}

The kinetic extraction process was investigated from the empirical model data of TPC obtained under the optimized condition. During the single factor study, it was observed that the trend of TPC followed that of the antioxidant activity. Therefore, the data of TPC was utilized during the kinetic study. The respective kinetic constants for each model are listed in Table 4. The first and second-order models were derived from Fick's diffusion laws, whereas, Page, Peleg, and Logarithmic models were derived based on moisture sorption curves (Cacace \& Mazza, 2003).

Table 4 Difference between Experimental and Predicted TPC Yield $(R S M E)$

\begin{tabular}{|c|r|c|r|}
\hline \multicolumn{1}{|c}{$\begin{array}{c}\text { Extraction } \\
\text { time } \\
(\mathrm{min})\end{array}$} & \multicolumn{2}{c}{$\begin{array}{c}\text { TPC yield (g GAE/g } \\
\text { extract) }\end{array}$} & $\begin{array}{c}\text { Difference } \\
(\%)\end{array}$ \\
\hline 45 & $0.0253 \pm 0.0002$ & 0.0241 & 5.03 \\
\hline 65 & $0.0250 \pm 0.0004$ & 0.0261 & 4.51 \\
\hline 85 & $0.0257 \pm 0.0002$ & 0.0273 & 6.47 \\
\hline
\end{tabular}

The validation of kinetic models was done by statistical correlations: $\mathrm{R}^{2}$ (coefficient) and RMSE (root mean square error). The fittings of the mentioned models to the experimental extraction data of TPC were in the order of Second-order kinetic model $>$ first-order kinetic model $>$ Logarithmic model $>$ Page's model $>$ Peleg's model $>$ Ponomaryov model. The second-order model was found to be the best to distinguish the extraction of antioxidants from red dates provided it had $\mathrm{R}^{2}(0.9849)$ closest to unity and least RMSE (0.001028). The kinetic graphs of all of the models are presented in Figure 2. 


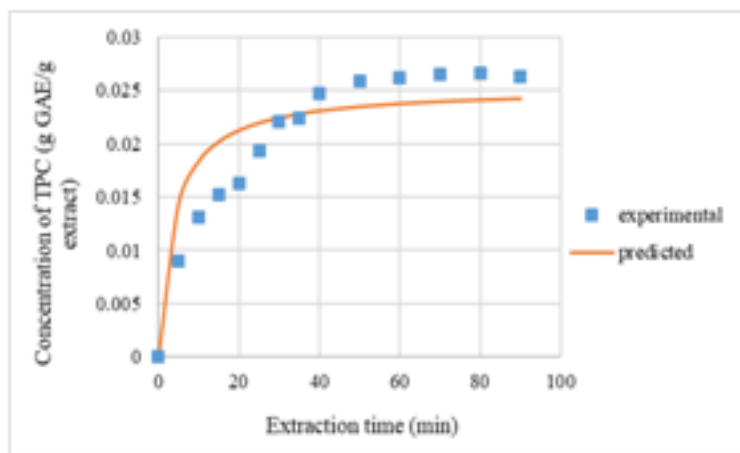

(a)

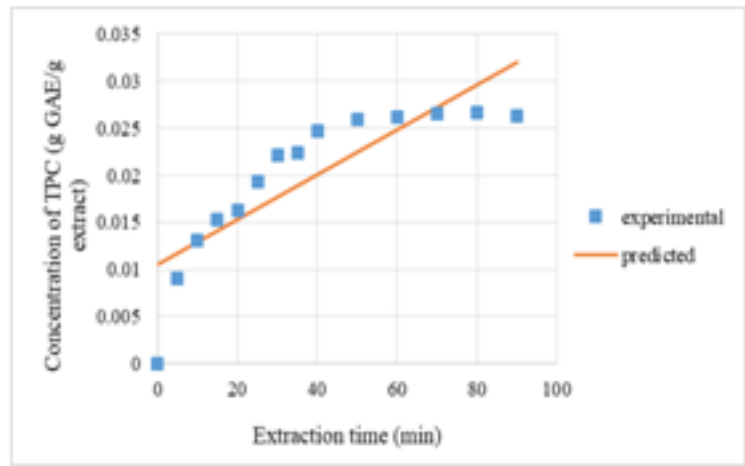

(c)

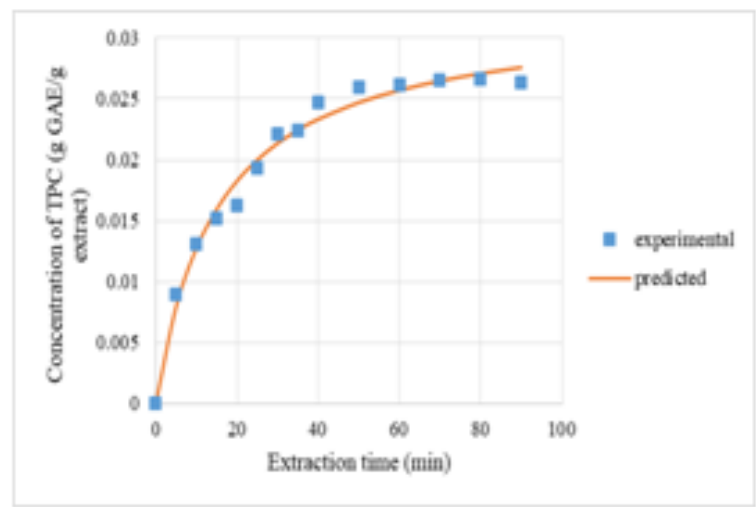

(e)

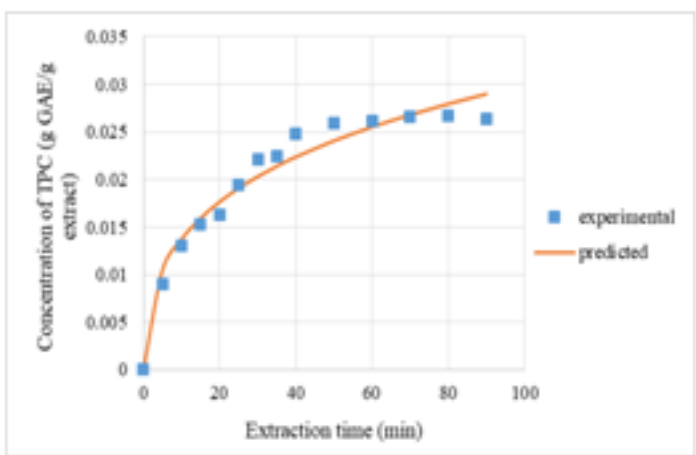

(b)

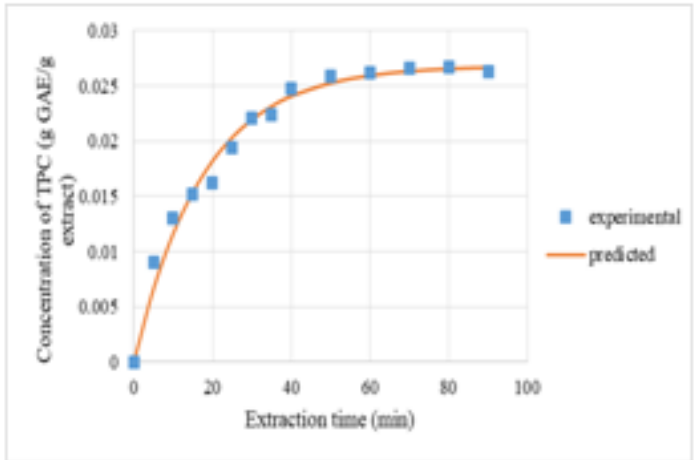

(d)

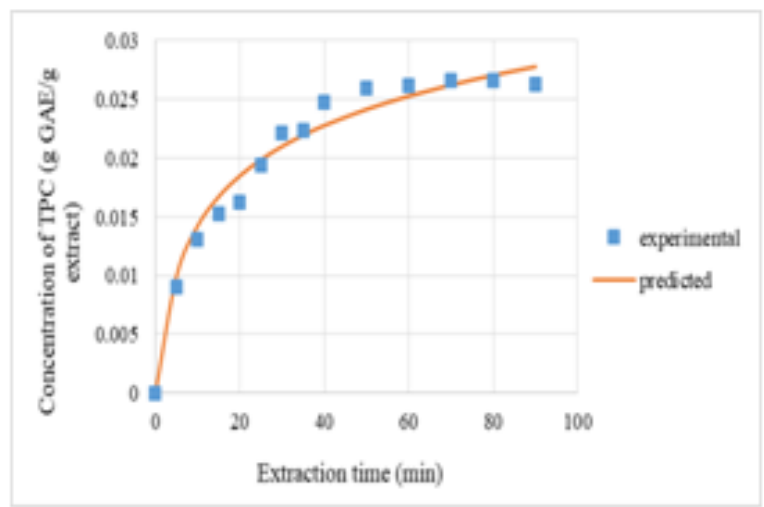

(f)

Figure 2 Kinetic Curves of Experimental and Predicted TPC of Red Dates (a) Peleg's Model (b) Page's Model (c) Ponomaryov's Model (d) First-Order Kinetic Model (e) Second-Order Kinetic Model (f) Logarithmic Model 


\subsubsection{Validation of Extraction Kinetic Model}

Further endorsement of the most accurate kinetic extraction mode was finalized to ensure its suitability and reliability by comparing the experimental with the predicted data of TPC under optimum extraction conditions for three different extraction periods of 45 , 65, and $85 \mathrm{~min}$ (Table 5). Respective Kinetic Variables of Six Empirical Models showed that the differences between two sets of data at 45,65 , and $85 \mathrm{~min}$ were $5.03 \%, 4.51 \%$, and $6.47 \%$. Therefore, the second-order kinetic model was selected to predict the extraction TPC of red dates at different extraction periods.

Table 5 Respective Kinetic Variables of Six Empirical Models

\begin{tabular}{|c|c|c|c|}
\hline Model name & $\begin{array}{l}\text { Calculated model } \\
\text { constants }\end{array}$ & $R^{2}$ & $R M S E$ \\
\hline Peleg's & $\begin{array}{l}k_{1}=148.1(\mathrm{~min} \\
\left.\mathrm{g}_{\text {extract }} / \mathrm{g} \text { GAE }\right) k_{2}= \\
39.65\left(\mathrm{~g}_{\text {extract }} / \mathrm{g} \text { GAE }\right)\end{array}$ & 0.824 & 0.003506 \\
\hline Page's & $k=5.241 n=-0.08715$ & 0.9663 & 0.001534 \\
\hline Ponomaryov & $\begin{array}{l}k_{3}=0.02623\left(\mathrm{~min}^{-1}\right) \\
b=2.157 \\
q_{e}=-0.009102 \\
\left(\mathrm{~g}_{\text {extract }} / \mathrm{g} \text { GAE }\right)\end{array}$ & 0.7160 & 0.004652 \\
\hline First-order & $\begin{array}{l}k_{l}=0.0568\left(\mathrm{~min}^{-1}\right) \\
C_{e}=0.02684\left(\mathrm{~g}_{\text {extract }} / \mathrm{g}\right. \\
\mathrm{GAE})\end{array}$ & 0.9826 & 0.01103 \\
\hline Second-order & $\begin{array}{l}k_{2}=2.017\left(\mathrm{~g}_{\text {extract }} / \mathrm{min}\right. \\
\mathrm{g} \mathrm{GAE}) C_{e}=0.03228 \\
\left(\mathrm{~g}_{\text {extract }} / \mathrm{g} \text { GAE }\right)\end{array}$ & 0.9849 & 0.001028 \\
\hline Logarithmic & $a=0.01422 b=0$ & 0.9740 & 0.0015 \\
\hline
\end{tabular}

\section{Conclusion}

In this research, the preservation and extraction of natura antioxidants from red dates were investigated through optimum drying temperature, extraction optimization, and kinetic studies An oven drying temperature of $60^{\circ} \mathrm{C}$ was found to be the optimum temperature that produced the highest crude extract yield, TPC, and DPPH antioxidant activity. The four-factor, three-level BBD design of RSM was used to optimize the UAE criteria for the extraction of antioxidants for parameters of solid-liquid ratio, temperature, ultrasound power, and time. The optimal extraction conditions were noted at $58.55 \mathrm{oC}$ with power, ratio, and time of $70 \%, 30 \mathrm{ml} / \mathrm{g}$, and $59.93 \mathrm{~min}$ respectively. The high correlation coefficient $\left(\mathrm{R}^{2}\right)$ confirmed the validity of the developed secondorder regression models for the responses of crude extract yield (0.8455), TPC (0.8042), and DPPH antioxidant activity (0.8120). The difference of DPPH antioxidant activity being less than $10 \%$ between the predicted (98.24\%) and actual (90.59\%) results obtained under the optimum extraction conditions further confirmed the validity of the proposed models. Additional comparisons with commercial synthetic antioxidants of BHT $(84.71 \%)$ and BHA $(77.73 \%)$ with optimized red dates $(90.59 \%)$ solidified its antioxidant potential. Based on $\mathrm{R}^{2}(0.9849)$ and RMSE (0.001028) value, kinetic studies revealed second-order model was the finest in describing the extraction of antioxidants from red dates. Overall, it can be concluded that red dates extract possesses strong antioxidant properties and can be taken into consideration as an alternate supply of potential herbal antioxidants in both food and pharma industries.

\section{Acknowledgment}

The authors would like to acknowledge that this work was supported by Taylor's university lakeside under the grant TRGS/MFS/1/2017/SOE/008.

\section{References}

Alahyane, A. Harrak H, Ayour J, Elateri I, Ait-Oubahou A, Benichou M (2019) Bioactive compounds and antioxidant activity of seventeen Moroccan date varieties and clones (Phoenix dactylifera L.). South African Journal of Botany 121: 402-409. doi: 10.1016/j.sajb.2018.12.004.

Ali A, Lim XY, Chong CH, Mah SH, Chua BL (2017) Optimization of ultrasound-assisted extraction of natural antioxidants from Piper betle using response surface methodology. LWT - Food Science and Technology 89:681-688. doi: 10.1016/j.1wt.2017.11.033.

Ali A, Lim XY, Chong CH, Mah SH, Chua BL (2018) Ultrasoundassisted extraction of natural antioxidants from betel leaves (Piper betle): Extraction kinetics and modeling. Separation Science and Technology 53(14): 2192-2205. doi: $10.1080 / 01496395.2018 .1443137$.

Alzorqi I, Singh A, Manickam S, Al-Qrimli HF (2017) Optimization of ultrasound assisted extraction (UAE) of $\beta$-dglucan polysaccharides from Ganoderma lucidum for prospective scale-up. Resource-Efficient Technologies 3(1): 46-54. https://doi.org/10.1016/j.reffit.2016.12.006.

Anuar N, Adnan AFM, Saat N, Aziz N, Taha RM (2013) Optimization of extraction parameters by using response surface 
methodology, purification, and identification of anthocyanin pigments in melastoma malabathricum fruit. The Scientific World Journal, Article ID 810547. doi: 10.1155/2013/810547.

Balyan U, Sarkar B (2017) Aqueous extraction kinetics of phenolic compounds from jamun (Syzygium cumini L.) seeds. International Journal of Food Properties 20(2): 372-389.

Bee Lin C, Yen Leng C (2018) Solid-Liquid Extraction Kinetics of Total Phenolic Compounds (TPC) from Red Dates. MATEC Web of Conferences 152: 1-17. doi: 10.1051/matecconf/201815201001.

Cacace JE, Mazza G (2003) Mass transfer process during extraction of phenolic compounds from milled berries. Journal of Food Engineering 59(4): 379-389.

Chemat F, Rombaut N, Sicaire AG, Meullemiestre A, FabianoTixier AS, Abert-Vian M (2017) Ultrasound assisted extraction of food and natural products. Mechanisms, techniques, combinations, protocols and applications. A review. Ultrasonics Sonochemistry 34: 540-560. doi: 10.1016/j.ultsonch.2016.06.035.

Choo CO, Chua BL, Figiel A, Jałoszyński K, et al. (2020) 'Hybrid drying of Murraya koenigii leaves: Energy consumption, antioxidant capacity, profiling of volatile compounds and quality studies. Processes 8(2): 240. doi: 10.3390/pr8020240.

Chua LYW, Chua BL, Figiel A, Chong CH, et al. (2019a) Drying of Phyla nodiflora leaves: Antioxidant activity, volatile and phytosterol content, energy consumption, and quality studies. Processes 7(4): 210. doi: 10.3390/pr7040210.

Chua LYW, Chong CH, Chua BL, Figiel A (2019b) Influence of Drying Methods on the Antibacterial , Antioxidant and Essential Oil Volatile Composition of Herbs: a Review. Food and Bioprocess Technology 12(3): 450-476. doi: 10.1007/s11947-0182227-x.

Dias ALB, Sergioa CSA, Santosa P, Barberob GF, Rezendec CA Martíneza J (2017) Ultrasound-assisted extraction of bioactive compounds from dedo de moça pepper (Capsicum baccatum L.) Effects on the vegetable matrix and mathematical modeling. Journal of Food Engineering 198: 36-44. doi: 10.1016/j.jfoodeng.2016.11.020.

Guerrero MS, Torres JS, Nuñez MJ (2008) Extraction of polyphenols from white distilled grape pomace: Optimization and modelling. Bioresource Technology 99(5): 1311-1318. doi: 10.1016/j.biortech.2007.02.009.

Harouna-Oumarou HA, Fauduet H, Porte C, Ho YS (2007) Comparison of kinetic models for the aqueous solid-liquid extraction of Tilia sapwood a continuous stirred tank reactor. Chemical Engineering Communications 194(4): 537-552. doi: $10.1080 / 00986440600992511$.

Al Harthi SS, Mavazhe A, Al-Mahroqi H, Khan SA (2015) Quantification of phenolic compounds, evaluation of physicochemical properties and antioxidant activity of four date (Phoenix dactylifera L.) varieties of Oman. Journal of Taibah University Medical Sciences 10(3): 346-352. doi: 10.1016/j.jtumed.2014.12.006.

Hii CL, Law CL, Cloke M (2009) Modeling using a new thin layer drying model and product quality of cocoa. Journal of Food Engineering 90(2): 191-198. doi: 10.1016/j.jfoodeng.2008.06.022.

Jokic S, Velic D, Bilic M, Bucic-Kojic A (2010) Modelling of the process of solid-liquid extraction of total polyphenols from soybeans. Czech Journal of Food Sciences 28(3): 206-212.

Kang Q, Chen S, Li S, Wang B, et al. (2019) Comparison on characterization and antioxidant activity of polysaccharides from Ganoderma lucidum by ultrasound and conventional extraction. International Journal of Biological Macromolecules 124 (1): 1137 1144. doi: 10.1016/j.ijbiomac.2018.11.215.

Kong F, Yu S, Feng Z, Wu X (2015) Optimization of ultrasonicassisted extraction of antioxidant compounds from Guava (Psidium guajava L.) leaves using response surface methodology. Pharmacognosy Magazine 11(43): 463-469.

López-Vidaña EC, Rojano BA, Figueroa IP, Zapata K, Cortes FB (2016) Evaluation of the sorption equilibrium and effect of drying temperature on the antioxidant capacity of the Jaboticaba (Myrciaria cauliflora). Chemical Engineering Communications 203(6): 809-821. doi: 10.1080/00986445.2015.1107721.

Moorthy IG, Prakash Maran J, Ilakya S, Anitha SL, et al. (2017) Ultrasound assisted extraction of pectin from waste Artocarpus heterophyllus fruit peel. Ultrasonics Sonochemistry 34: 525-530.

Morales P, Ferreira ICFR, Carvalho AM, Sanchez-Mata MC, et al. (2014) Mediterranean non-cultivated vegetables as dietary sources of compounds with antioxidant and biological activity. LWT Food Science and Technology 55(1): 389-396. doi: 10.1016/j.lwt.2013.08.017.

Ngo TV, Scarlett CJ, Bowyer MC, Ngo PD, et al. (2017) Impact of Different Extraction Solvents on Bioactive Compounds and Antioxidant Capacity from the Root of Salacia chinensis L. Journal of Food Quality 2017. Article ID 9305047. https://doi.org/10.1155/2017/9305047. 
Paunović DD, Mitic SS, Kostic D, Mitic M (2014) 'Kinetics and Thermodynamics of the Solid-Liquid Extraction Process of Total Polyphenols from Barley. Savremene Tehnologije 3(2):58-63.

Qu W, Pan Z, Ma H (2010) Extraction modeling and activities of antioxidants from pomegranate marc. Journal of Food Engineering 99(1): 16-23.

Toğrul İT, Pehlivan D (2004) Modelling of thin layer drying kinetics of some fruits under open-air sun drying process. Journal of Food Engineering 65(3): 413-425.
Xu DP, Zheng J, Zhou Y, Li Y, Li S, Li HB (2017) Ultrasoundassisted extraction of natural antioxidants from the flower of Limonium sinuatum: Optimization and comparison with conventional methods. Food Chemistry 217: 552-559.

Zhou Y, Zheng J, Gan RY, Zhou T, Xu DP, Li HB (2017) Optimization of ultrasound-assisted extraction of antioxidants from the mung bean coat. Molecules 22(4): 638. doi: 10.3390/molecules22040638. 